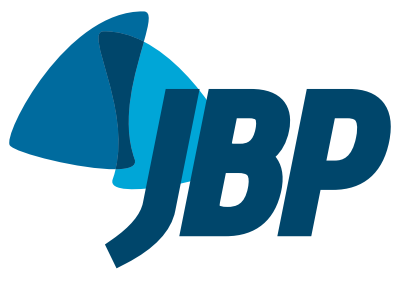

\title{
Evaluating bronchodilator response in pediatric patients with post-infectious bronchiolitis obliterans: use of different criteria for identifying airway reversibility
}

\author{
Rita Mattiello', Paula Cristina Vidal'2, Edgar Enrique Sarria ${ }^{3}$, \\ Paulo Márcio Pitrez 1 , Renato Tetelbom Stein', Helena Teresinha Mocelin 4 , \\ Gilberto Bueno Fischer ${ }^{4}$, Marcus Herbert Jones ${ }^{1}$, Leonardo Araújo Pinto ${ }^{1}$
}

1. Centro Infant, Instituto de Pesquisas Biomédicas, Pontifícia Universidade Católica do Rio Grande do Sul - PUCRS - Porto Alegre (RS) Brasil.

2. Universidade Regional Integrada do Alto Uruguai e das Missões - URI - Erechim (RS) Brasil.

3. Curso de Medicina, Universidade de Santa Cruz do Sul - UNISC - Santa Cruz do Sul (RS) Brasil.

4. Universidade Federal de Ciências da Saúde de Porto Alegre - UFCSPA Porto Alegre (RS) Brasil.

Submitted: 6 April 2015

Accepted: 30 November 2015

Study carried out at the Instituto de Pesquisas Biomédicas, Centro Infant, Pontifícia Universidade Católica do Rio Grande do Sul, Porto Alegre (RS), Brasil.

\begin{abstract}
Objective: Post-infectious bronchiolitis obliterans (PIBO) is a clinical entity that has been classified as constrictive, fixed obstruction of the lumen by fibrotic tissue. However, recent studies using impulse oscillometry have reported bronchodilator responses in PIBO patients. The objective of this study was to evaluate bronchodilator responses in pediatric PIBO patients, comparing different criteria to define the response. Methods: We evaluated pediatric patients diagnosed with PIBO and treated at one of two pediatric pulmonology outpatient clinics in the city of Porto Alegre, Brazil. Spirometric parameters were measured in accordance with international recommendations. Results: We included a total of 72 pediatric PIBO patients. The mean pre- and post-bronchodilator values were clearly lower than the reference values for all parameters, especially $\mathrm{FEF}_{25-75 \%}$. There were post-bronchodilator improvements. When measured as mean percent increases, $\mathrm{FEV}_{1}$ and $\mathrm{FEF}_{25-75 \%}$, improved by $11 \%$ and $20 \%$, respectively. However, when the absolute values were calculated, the mean $\mathrm{FEV}_{1}$ and $\mathrm{FEF}_{25-75 \%}$ both increased by only $0.1 \mathrm{~L}$. We found that age at viral aggression, a family history of asthma, and allergy had no significant effects on bronchodilator responses. Conclusions: Pediatric patients with PIBO have peripheral airway obstruction that is responsive to treatment but is not completely reversible with a bronchodilator. The concept of PIBO as fixed, irreversible obstruction does not seem to apply to this population. Our data suggest that airway obstruction is variable in PIBO patients, a finding that could have major clinical implications.
\end{abstract}

Keywords: Bronchiolitis obliterans; Infection/complications; Airway obstruction;

Bronchodilator agents.

\section{INTRODUCTION}

Bronchiolitis obliterans is a form of chronic obstructive lung disease secondary to a severe insult to the lower respiratory tract. The disease is characterized by the narrowing of the distal airways, which leads to a chronic obstructive disorder. In children, the most common form is post-infectious bronchiolitis obliterans (PIBO), ${ }^{(1,2)}$ There are reports of PIBO secondary to infection with influenza, parainfluenza, respiratory syncytial virus, and Mycoplasma pneumonia; however, certain adenovirus serotypes seem to be the infectious agents most likely linked with PIBO. ${ }^{(2-4)}$ Although PIBO has been reported in several different regions in the world, South American countries have historically reported the highest numbers of cases.(1) In most of those reports, PIBO has been classified as constrictive airway disease, presenting some degree of luminal occlusion by fibrous tissue, together with chronic inflammation. Total obliteration of the lumen by fibrotic tissue has been observed in up to $23 \%$ of patients. . $^{(4,5)}$
A diagnosis of PIBO should be made not only on the basis of a suggestive clinical history and characteristic HRCT findings but also on that of spirometric evidence of moderate to severe obstructive impairment. $(6,7)$ Some authors consider PIBO a disorder involving fixed obstruction. However, there is some controversy in the aspect of pulmonary function in PIBO patients, which calls for further research at various levels.

The question of the response to the use of a bronchodilator in patients with PIBO is an important one, given its potential impact in the clinical management of PIBO. Most authors believe that PIBO patients would not show a significant bronchodilator response, since there is considerable evidence that these subjects present with fixed airway obstruction. ${ }^{(1,6-9)}$ However, in one previous study, it was reported that patients diagnosed with PIBO showed such a response. (7) In the present study, we evaluated bronchodilator responses in a large sample of pediatric patients diagnosed with PIBO, comparing different criteria to define the significance of the response.

\section{Correspondence to:}

Leonardo A. Pinto. Instituto de Pesquisas Biomédicas, Centro Infant, Avenida Ipiranga, 6690, $2^{\circ}$ andar, CEP 90610-000, Porto Alegre, RS, Brasil.

Tel.: 5551 3320-3000 or 5551 3320-2221. Fax: 5551 3320-3000.E-mail: leonardo.pinto@pucrs.br

Financial support: This study received financial support from the Brazilian Conse/ho Nacional de Desenvolvimento Cientifico e Tecnológico ICNPq, National Council for Scientific and Technological Development), the Coordenação de Aperfeiçoamento de Pessoal de Nive/ Superior (CAPES, Office for the Advancement of Higher Education), and the Fundação de Amparo à Pesquisa do Estado do Rio Grande do Su/(FAPERGS, Foundation for the Support of Research in the State of Rio Grande do Sul). 


\section{METHODS}

\section{Patients and procedures}

This was a cross-sectional study involving children and adolescents with PIBO, all of whom had previously been diagnosed with PIBO and were under follow-up treatment at pediatric pulmonology outpatient clinics at one of two university hospitals in the city of Porto Alegre, Brazil: the Hospital São Lucas, operated by the Pontifical Catholic University of Rio Grande do Sul; or the Santo Antônio Children's Hospital, which is part of the Santa Casa Hospital Complex. The mean age of the patients was 10 years (range, 4-17 years). The medical staff at both hospitals have clinical expertise in diagnosing PIBO in pediatric patients. For the purposes of this study, we included spirometry results for all of the patients. All of the spirometry tests performed at the two hospitals met the American Thoracic Society/ European Respiratory Society (ATS/ERS) requirements for acceptability and reproducibility. ${ }^{(10)}$

The diagnosis of PIBO was based on a combination of clinical, epidemiologic, and imaging data, as previously described. ${ }^{(1)}$ All diagnoses of PIBO were made on the basis of the following criteria: having had acute, severe bronchiolitis or viral pneumonia during the first two years of life after having previously been healthy; presenting with evidence of persistent airway obstruction after the acute event (identified either by physical examination or by pulmonary function testing); presenting with chest X-ray findings indicative of chronic lung disease (e.g., hyperinflation, atelectasis, airway wall thickening, and bronchiectasis); presenting with chest $\mathrm{CT}$ findings of a mosaic pattern and air trapping. A diagnosis of PIBO was ruled out if the patient had any other condition that progresses to permanent respiratory symptoms, including chronic lung diseases such as cystic fibrosis and bronchopulmonary dysplasia, as well as immunodeficiency disorders. Family histories of asthma and allergy (rhinitis, eczema, etc.) were taken at regular clinical visits.

Spirometric parameters (FVC, $\mathrm{FEV}_{1}, \mathrm{FEF}_{25-75 \% \text {, }}$ and the $\mathrm{FEV}_{1} / \mathrm{FVC}$ ratio) were measured in accordance with international recommendations for acceptability and reproducibility. ${ }^{(10)}$ The pulmonary function parameters were measured only if patients had been free of respiratory exacerbations and clinically stable for at least two weeks. Prior to the tests, short- and long-acting $\beta_{2}$ agonists were withheld for 12 and $48 \mathrm{~h}$, respectively, although inhaled corticosteroids were maintained as prescribed. Spirometric values were chosen from the best three acceptable, reproducible FVC maneuvers, and the one with the greatest sum of FVC and FEV ${ }_{1}$ was selected. Reference values and equations employed for spirometry were those described by Stanojevic et al. ${ }^{(11)}$ All pulmonary function data are expressed as $z$-score values. The severity of functional impairment was defined on the basis of the $\mathrm{FEV}_{1}$, in accordance with the ATS/ERS recommendations. ${ }^{(10)}$ The main methods for analyzing bronchodilator responses are described in Chart 1. In addition, we analyzed factors that could have influenced the bronchodilator response.

\section{Statistical analysis}

Continuous variables are expressed as mean \pm standard deviation or as median and interquartile range, whereas categorical variables are expressed as absolute and relative frequencies. Each pulmonary function parameter was expressed as a z-score, using the regression equation and variance derived from reference population values. ${ }^{(8,11)}$ To analyze bronchodilator response data, we used the generalized estimating equation procedure ${ }^{(10-13)}$ of a generalized linear model, which allows the analysis of repeated measures; the working correlation matrix was autoregressive. ${ }^{(14)} \mathrm{A}$ linear mixed model was used to determine whether bronchodilator responses (outcomes) were affected by patient age at the time of viral aggression, by a family history of asthma, or by allergy. For all analyses, the level of statistical significance was set at $p<0.05$. Data processing and analysis were performed with IBM SPSS Statistics software package, version 18.0 (IBM Corporation, Armonk, NY, USA).

The study was approved by the local research ethics committees of both institutions. All participating patients verbally consented to be included in the study, and the parents or legal guardians of the participants gave written informed consent.

\section{RESULTS}

We evaluated a total of 72 pediatric patients with PIBO. The patients had been monitored periodically, from infancy, at outpatient clinics. The characteristics of the study sample are shown in Table 1 . Of the 72 patients evaluated, 55 (76.4\%) were male. Most of the patients had been diagnosed with PIBO during the first year of life.

The pulmonary function parameters of the patients, expressed as z-score values, are presented in Table 2. The mean pre- and post-bronchodilator values for all parameters were abnormal, especially those for $\mathrm{FEF}_{25-75 \%}$. There were significant post-bronchodilator improvements in expiratory flows, although the values did not reach normality for age. As can be seen in Table 3, the improvements were significant when the mean percent variation from the previous measurement was calculated (increases of $11 \%$ and $20 \%$ for $\mathrm{FEV}_{1}$ and $\mathrm{FEF}_{25-75 \%}$, respectively). However,

Chart 1. Description of different methods (equations) for calculating a bronchodilator response.

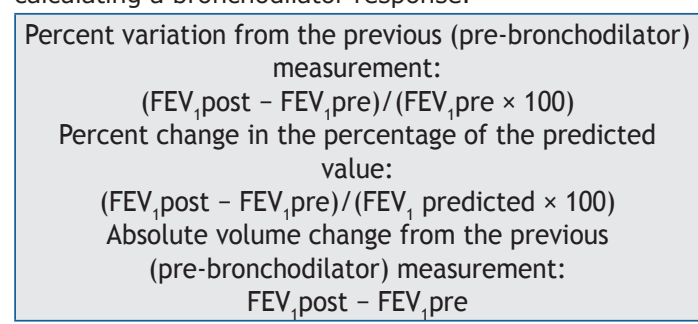

Post: post-bronchodilator; and pre: pre-bronchodilator. 
when the mean absolute volume change was calculated, the improvements were more modest (only $0.1 \mathrm{~L}$ for $\mathrm{FEV}_{1}$ and $\mathrm{FEF}_{25-75 \%}$ alike).

In the multivariate analysis of the outcome variables (Table 4), none of the predictor variables (age at viral aggression, allergy, and asthma family history) remained in the models. We found that age at viral aggression, a family history of asthma, and allergy had no significant effect on the bronchodilator response.

\section{DISCUSSION}

Of the 72 pediatric PIBO patients, 42 (58.3\%) demonstrated a significant bronchodilator response when the cut-off point was a percent change of $9 \%$, as employed by Jones et al. ${ }^{(12)}$ When we used a cut-off point of $12 \%$, as recommended by the ATS/ERS and in other studies, ${ }^{(10,13)}$ the bronchodilator response was still significant in 34 patients (47.2\%).

Although there is no consensus about what constitutes reversibility, the three most common methods of expressing bronchodilator response are as a percent change in relation to the initial spirometric value, as a percent change in the percentage of the predicted value, and as an absolute volume change. In the present study, we analyzed reversibility by all three methods (Table 3). Expressing the change in $\mathrm{FEV}_{1}$ or FVC as a percentage of the predicted value has been reported to have advantages over expressing it as a percent change from baseline. ${ }^{(15)}$ The ATS/ERS guidelines recommend using the percent change from baseline and the absolute change in $\mathrm{FEV}_{1}$ or FVC to characterize the bronchodilator response in an individual subject. According to Pellegrino et al., post-bronchodilator increases in $\mathrm{FEV}_{1}$ of $12 \%$ and $200 \mathrm{~mL}$ changes from baseline during a single spirometry session both suggest that the degree of bronchodilation is "significant". ${ }^{(13)}$ As a caveat, the authors stressed that the lack of a response during bronchodilator testing does not exclude the possibility of a subsequent clinical response to bronchodilator therapy.

Table 1. Characteristics of pediatric patients with postinfectious bronchiolitis obliterans. ${ }^{\text {a }}$

\begin{tabular}{lc}
\multicolumn{1}{c}{ Variable } & (N = 72) \\
Gender, male & $55(76)$ \\
Age, years & $10(4-17)$ \\
Age at viral aggression, months & $11(1-36)$ \\
Allergy & $38(53)$ \\
Asthma family history & $22(31)$
\end{tabular}

avalues expressed as $\mathrm{n}(\%)$ or as mean (range).

Table 2. Lung function parameters expressed as z-scores for pediatric patients with post-infectious bronchiolitis obliterans $(\mathrm{N}=72){ }^{\text {a }}$

\begin{tabular}{lcc}
\multicolumn{1}{c}{ Variable } & Pre-BD & Post-BD \\
\hline FVC (z-score) & $-2.47 \pm 1.51$ & $-2.07 \pm 1.51$ \\
FEV $_{1}$ (z-score) & $-4.00 \pm 1.59$ & $-3.52 \pm 1.69$ \\
FEV $_{1} /$ FVC (z-score) & $-2.60 \pm 0.88$ & $-2.32 \pm 1.02$ \\
FEF $_{25-75 \%}$ (z-score) & $-4.14 \pm 1.35$ & $-3.73 \pm 1.59$ \\
\hline
\end{tabular}

BD: bronchodilator. ${ }^{a}$ Values expressed as mean \pm SD.
In a study conducted in Argentina in 1999, Teper et al. reported fixed bronchial obstruction in 13 infants with chronic lung disease after severe adenovirus infection. ${ }^{(16)}$ Since then, it has been accepted that PIBO should be considered an irreversible COPD. However, that conclusion was based only on the fact that the degree of improvement in those infants failed to reach the $30 \%$ cut-off point considered the threshold for confirming bronchodilation, which is different than showing no response. More than two decades later, Castro-Rodriguez et al., using impulse oscillometry rather than spirometry, observed a significant bronchodilator response in children with PIBO in Chile. ${ }^{(8)}$ The concept that PIBO is characterized by irreversible obstruction could be explained either by the small caliber of the airways in young children, which makes it difficult to quantify bronchodilation in pulmonary function tests, or by acquired airway hyperreactivity later in life.

The percent change in $\mathrm{FEV}_{1}$ after bronchodilator administration in the general population varies across studies, depending on whether the study sample comprises adults or school-age children. In a study involving children between 5 and 10 years of age, the cut-off point that provided the best balance of sensitivity and specificity for a bronchodilator response was that of a $9 \%$ change in $\mathrm{FEV}_{1}$, measured as a percentage of the predicted value. ${ }^{(15)}$ A similar cut-off point was found adequate to indicate bronchodilation in a population of school-age children ( $\geq 6$ years of age) in Spain. ${ }^{(17)}$ When we applied such a cut-off point, most of our patients showed a significant bronchodilator response. When we attempted to identify the factors associated with the high rate of bronchodilator response in our sample, we found that neither age at viral aggression, nor a family history of asthma, nor allergy had any significant effect on the magnitude of the bronchodilator response.

Reversibility of airway obstruction could indicate an innate predisposition to PIBO in children who have previously (prior to the triggering viral event) had a phenotype of airway hyperreactivity. ${ }^{(8)}$ Alternatively, children with PIBO might present with variable, rather than fixed, airway obstruction, which would allow different degrees of reversibility. It is important to note that when the measure was an absolute volume change, we observed a median increase of only 0.1 $L$, and the significance of such a small variation is questionable. In children who develop PIBO, the most severe obstruction is at the level of lower airways, which could explain the higher $\beta_{2}$ agonist responses we observed in terms of the $\mathrm{FEF}_{25-75 \%}$. However, $\mathrm{FEF}_{25-75 \%}$ is considered highly variable in control groups, and such variation is therefore not easily interpreted. ${ }^{(13)}$ For $\mathrm{FEV}_{1}$, the determination of a percent change from the initial value might reflect airflow limitation, but it is considered more dependent of the pre-bronchodilator $\mathrm{FEV}_{1}$ value than on other components of the process. ${ }^{(18)}$ In our PIBO subjects, the degree of bronchodilation was likely related to the degree of baseline obstruction secondary to complex disrupted bronchiolar functioning, 
Table 3. Bronchodilator response in pediatric patients with post-infectious bronchiolitis obliterans, considering the different methods to define reversibility. ${ }^{a}$

\begin{tabular}{lc}
\multicolumn{1}{c}{ Variable } & BD response \\
\hline $\mathrm{FEV}_{1}$ (\% change from previous) & $11.05(4.40-19.85)$ \\
$\mathrm{FEF}_{25-75 \%}$ (\% change from previous) & $20.00(2.10-40.57)$ \\
$\mathrm{FEV}_{1}$ (change in \% of predicted) & $5.26(2.47-10.33)$ \\
$\mathrm{FEF}_{25-75 \%}$ (change in \% of predicted) & $3.85(0.31-9.68)$ \\
$\mathrm{FEV}_{1}$ (absolute volume change, in L) & $0.10(0.04-0.18)$ \\
$\mathrm{FEF}_{25-75 \%}$ (absolute volume change, in L) & $0.10(0.01-0.24)$ \\
\hline
\end{tabular}

BD: bronchodilator. ${ }^{a}$ Values expressed as median (interquartile range).

Table 4. Analysis of factors with a potential influence on bronchodilator responses in pediatric patients with postinfectious bronchiolitis obliterans (general linear model-based approach).

\begin{tabular}{|c|c|c|c|}
\hline \multicolumn{4}{|c|}{$\mathrm{FEV}, \mathrm{BD}$ response, \% change from previous } \\
\hline Age at viral aggression, months & 0.02 & $(-0.25$ to 0.31$)$ & 0.853 \\
\hline Allergy & 3.06 & $(-2.89$ to 9.02$)$ & 0.313 \\
\hline Family history of asthma & 1.66 & $(-4.02$ to 7.35$)$ & 0.566 \\
\hline \multicolumn{4}{|c|}{$\mathrm{FEV}, \mathrm{BD}$ response, change in $\%$ of predicted } \\
\hline Age at viral aggression, months & 0.02 & $(-0.10$ to 0.15$)$ & 0.712 \\
\hline Allergy & 2.06 & $(-0.71$ to 4.84$)$ & 0.145 \\
\hline Family history of asthma & -0.77 & $(-3.55$ to 1.99$)$ & 0.582 \\
\hline \multicolumn{4}{|c|}{$\mathrm{FEV}_{1} \mathrm{BD}$ response, absolute volume change } \\
\hline Age at viral aggression, months & 0.00 & $(-0.00$ to 0.00$)$ & 0.859 \\
\hline Allergy & 0.03 & $(-0.01$ to 0.08$)$ & 0.193 \\
\hline Family history of asthma & 0.00 & $(-0.05$ to 0.05$)$ & 0.932 \\
\hline
\end{tabular}

BD: bronchodilator.

which includes chronic inflammatory process, scarring, altered bronchomotor tone, and air trapping.

It is difficult to estimate the impact of a median increase in $\mathrm{FEV}_{1}$ of $0.1 \mathrm{~L}$ ( $11 \%$ over the pre-bronchodilator value) in pediatric patients with PIBO that have very severe obstruction. However, in the context of a baseline FEV $_{1} z$-score of -2.47 , our finding should not be underestimated. There is controversy regarding reversibility of airway obstruction in PIBO. Given the variability of the within-individual bronchodilator response among healthy subjects, there is probably no single test or method that can properly assess this complex response, especially in subjects with severely obstruction, who might present greater variability. In addition, as the ATS/ERS guidelines recommend, ${ }^{(10)} \mathrm{a}$ longitudinal assessment of the response over a period of several weeks should be preferred over single assessments. ${ }^{(19-21)}$ A lack of improvement in FEV after a bronchodilator test might be a disincentive to performing a clinical trial with $\beta_{2}$ agonists.

On the basis of our findings in the present study, we conclude that pediatric PIBO patients have peripheral airway obstruction that can improve with the use of $\beta_{2}$ agonists. Although the lung function of such patients does not achieve normality after the use of a bronchodilator, it certainly shows a response that could provide a perceived clinical benefit. For such knowledge to have therapeutic applications, however, further clinical trials are needed in order to assess the true effectiveness of the long-term use of bronchodilators in patients diagnosed with PIBO.

\section{REFERENCES}

1. Castro-Rodriguez JA, Giubergia V, Fischer GB, Castaños C, Sarria EE, Gonzalez R, et al. Postinfectious bronchiolitis obliterans in children: the South American contribution. Acta Paediatr. 2014;103(9):913-21. http://dx.doi.org/10.1111/apa.12689

2. Fischer GB, Sarria EE, Mattiello R, Mocelin HT, Castro-Rodriguez JA. Post infectious bronchiolitis obliterans in children. Paediatr Respir Rev. 2010;11(4):233-9. http://dx.doi.org/10.1016/j.prrv.2010.07.005

3. Colom AJ, Teper AM, Vollmer WM, Diette GB. Risk factors for the development of bronchiolitis obliterans in children with bronchiolitis. Thorax. 2006;61(6):503-6. http://dx.doi.org/10.1136/thx.2005.044909

4. Zhang $L$, Silva FA. Bronchiolitis obliterans in children [Article in Portuguese]. J Pediatr (Rio J). 2000;76(3):185-92. http://dx.doi. org/10.2223/JPED.49

5. Mauad T, Dolhnikoff M; São Paulo Bronchiolitis Obliterans Study Group. Histology of childhood bronchiolitis obliterans. Pediatr Pulmonol. 2002;33(6):466-74. http://dx.doi.org/10.1002/ppul.10097
6. Mattiello R, Mallol J, Fischer GB, Mocelin HT, Rueda B, Sarria EE. Pulmonary function in children and adolescents with postinfectious bronchiolitis obliterans. J Bras Pneumol. 2010;36(4):453-9. http:// dx.doi.org/10.1590/S1806-37132010000400010

7. Mattiello R, Sarria EE, Stein R, Fischer GB, Mocelin HT, Barreto SS et al. Functional capacity assessment in children and adolescents with post-infectious bronchiolitis obliterans. J Pediatr (Rio J). 2008;84(4):337-43. http://dx.doi.org/10.2223/jped.1807

8. Castro-Rodriguez JA, Daszenies C, Garcia M, Meyer R, Gonzales $R$. Adenovirus pneumonia in infants and factors for developing bronchiolitis obliterans: a 5-year follow-up. Pediatr Pulmonol. 2006;41(10):947-53. http://dx.doi.org/10.1002/ppul.20472

9. Cazzato S, Poletti V, Bernardi F, Loroni L, Bertelli L, Colonna S, et al. Airway inflammation and lung function decline in childhood postinfectious bronchiolitis obliterans. Pediatr Pulmonol. 2008;43(4):38190. http://dx.doi.org/10.1002/ppul.20784 
10. Miller MR, Hankinson J, Brusasco V, Burgos F, Casaburi R, Coates A et al. Standardisation of spirometry. Eur Respir J. 2005;26(2):319-38. http://dx.doi.org/10.1183/09031936.05.00034805

11. Stanojevic S, Wade A, Cole TJ, Lum S, Custovic A, Silverman M, et al. Spirometry centile charts for young Caucasian children: the Asthma UK Collaborative Initiative. Am J Respir Crit Care Med. 2009;180(6):547-52. http://dx.doi.org/10.1164/rccm.200903-03230C

12. Jones $M$, Castile R, Davis $S$, Kisling J, Filbrun D, Flucke $R$, et al. Forced expiratory flows and volumes in infants. Normative data and lung growth. Am J Respir Crit Care Med. 2000:161(2 Pt 1):353-9. http://dx.doi.org/10.1164/ajrccm.161.2.9903026

13. Pellegrino R, Viegi G, Brusasco V, Crapo RO, Burgos F, Casaburi R, et al. Interpretative strategies for lung function tests. Eur Respir $J$ 2005;26(5):948-68. http://dx.doi.org/10.1183/09031936.05.00035205

14. Edwards LJ. Modern statistical techniques for the analysis of longitudinal data in biomedical research. Pediatr Pulmonol. 2000;30(4):330-44 0496(200010)30:4<330\%:AID-PPUL10>3.0.CO;2-D

15. Dundas I, Chan EY, Bridge PD, McKenzie SA. Diagnostic accuracy of bronchodilator responsiveness in wheezy children. Thorax. 2005;60(1):13-6. http://dx.doi.org/10.1136/thx.2004.029934
16. Teper AM, Kofman CD, Maffey AF, Vidaurreta SM. Lung function in infants with chronic pulmonary disease after severe adenovira illness. J Pediatr. 1999;134(6):730-3. http://dx.doi.org/10.1016/ S0022-3476(99)70289-1

17. Pardos Martínez C, Fuertes Fernández-Espinar J, Nerín De la Puerta I, González Pérez-Yarza E. Cut-off point for a positive bronchodilation test [Article in Spanish]. An Esp Pediatr. 2002;57(1):5-11. http:// dx.doi.org/10.1016/S1695-4033(02)77885-5

18. Brand PL, Quanjer PH, Postma DS, Kerstjens HA, Koëter GH Dekhuijzen PN, et al. Interpretation of bronchodilator response in patients with obstructive airways disease. The Dutch Chronic NonSpecific Lung Disease (CNSLD) Study Group. Thorax. 1992;47(6):42936. http://dx.doi.org/10.1136/thx.47.6.429

19. O'Donnell $D E$. Assessment of bronchodilator efficacy in symptomatic COPD: is spirometry useful? Chest. 2000;117(2 Suppl):42S-7S http://dx.doi.org/10.1378/chest.117.2_suppl.42S

20. Wang $W$, Shen KL, Zeng JJ. Clinical studies of children with bronchiolitis obliterans [Article in Chinese]. Zhonghua Er Ke Za Zhi. 2008;46(10):732-8

21. Wang $Y T$, Thompson $L M$, Ingenito EP, Ingram RH Jr. Effects of increasing doses of beta-agonists on airway and parenchymal hysteresis. J Appl Physiol (1985). 1990;68(1):363-8. 